\title{
Cabaña ED
}

\author{
Lorena Troncoso Valencia
}

Reseña de proyecto arquitectónico

Nombre del Proyecto: Cabaña ED

Arquitecto: Lorena Troncoso Valencia

Sitio Web: http://www.lorenatroncoso.cl/

E-mail: lorenatroncosov@gmail.com

Ubicación: Las Trancas, Pinto, Chile.

\begin{abstract}
Año construcción: 2016
\end{abstract}
Superficie construida: $105 \mathrm{~m} 2$

Fotógrafo / Sitio web: Cristóbal Caro

Construcción: Constructora Bocaz, Chillán.

Sitio Web: http://www.constructorabocaz.cl/

Recibido: 10 de julio de 2017

Aprobado: 20 de octubre de 2017

\section{Resumen:}

Este proyecto denominado Cabaña Ed, de la arquitecta chilena Lorena Troncoso Valencia, es parte de una serie de obras emplazadas en la comuna de Pinto, Región de Nuble de Chile. Zona de frondosa vegetación de árboles autóctonos y con fugas visuales hacia la cordillera de los Andes. La Cabaña Ed, donde predomina el uso de la madera, se integra muy sutilmente con ese entorno natural. En la edición de REVISTARQUIS 11, se presentó otro proyecto de la Arquitecta ubicado en esa misma zona.

Palabras clave: arquitectura chilena; cabaña; madera.

\section{Cabin ED}

\section{Abstract:}

Cabin ED, by the Chilean architect Lorena Troncoso Valencia, is part of a series of works located in the commune of Pinto, Ñuble Region, Chile. This area is characterized by lush vegetation of native trees and visual towards the Andes leaks. In this project the use of wood predominates, which is subtly integrated with the natural environment. In the edition of REVISTARQUIS 11, another project of the architect, located in that same zone of tourist development was presented.

Keywords: chilean architecture; cabin; wood. 
- I proyecto está ubicado en el centro sur de Chile, Pinto. Una localidad cordillerana reconocida por el turismo en deportes extremos de alta montaña.

El lugar donde se emplaza el proyecto presenta frondosa vegetación de árboles autóctonos con vista hacia la cordillera de Los Andes, además en medio del terreno hay una pequeña quebrada con un desnivel de 15 metros aprox. sobre la cual se emplaza el proyecto.

La cabaña se plantea de forma triangular asimétrica en su parte superior, inspirada en la forma icónica de la montaña que se aprecia a sus espaldas. Se orienta hacia el norte que a la vez coincide con la caída quebrada, aprovechando el paisaje desde la terraza y el mayor asoleamiento.

El proyecto se concibe como un gran espacio con dos niveles, comunicados entre sí por una doble altura y una zona de dormitorios en el primer nivel. En el espacio central se encuentra la cocina y sala de estar que se conecta espacialmente con el dormitorio del segundo nivel y a la vez este se conecta a través de un puente con una zona de escritorio. Todos estos espacios se proyectan hacia la terraza principal que mira a la quebrada.

El ventanal de la fachada principal se retrae en forma diagonal para generar sombra en época de mayor asoleamiento.

Las grandes trasparencias acogen el abundante follaje de los árboles en el interior de la cabaña, fundiendo el exterior e interior, permitiendo una mayor permeabilidad.

Se genera un espacio interior semi abierto en la parte posterior, que funciona como acceso secundario y patio interior necesario para las épocas de lluvia. Se conecta con la terraza principal a través de una terraza lateral.

La estructura se basa en una plataforma elevada sostenida por apoyos triangulados de madera. Sobre esta se construyen la estructura de muros que vigas a la vista asimétrica que dan la forma a la cabaña. Se usaron algunas vigas de acero que en forma colaborativa con madera permiten mayor cobertura espacial. La cabaña se reviste de tabla horizontal negra que realza la presencia del verde circundante. Mientras que en el interior se genera contraste entre la madera y el murallón de piedra.

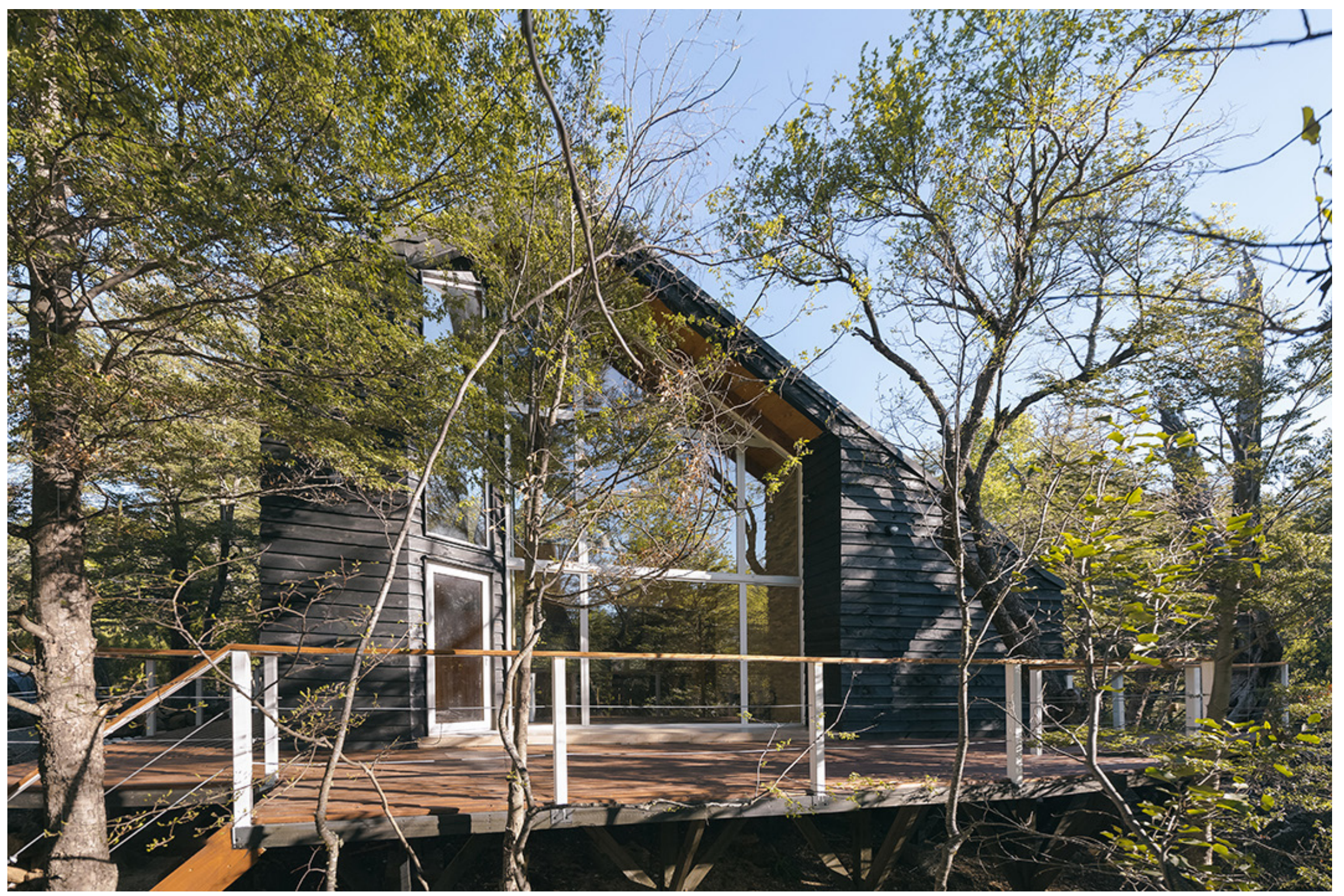


Cabaña ED es el inicio de una serie de obras, que se diseñan pensando en el refugio del hombre y escenario de la naturaleza a la vez. Aprovechando lo construido para alcanzar la contemplación del entorno.

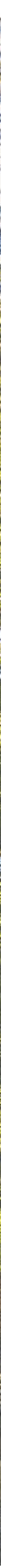



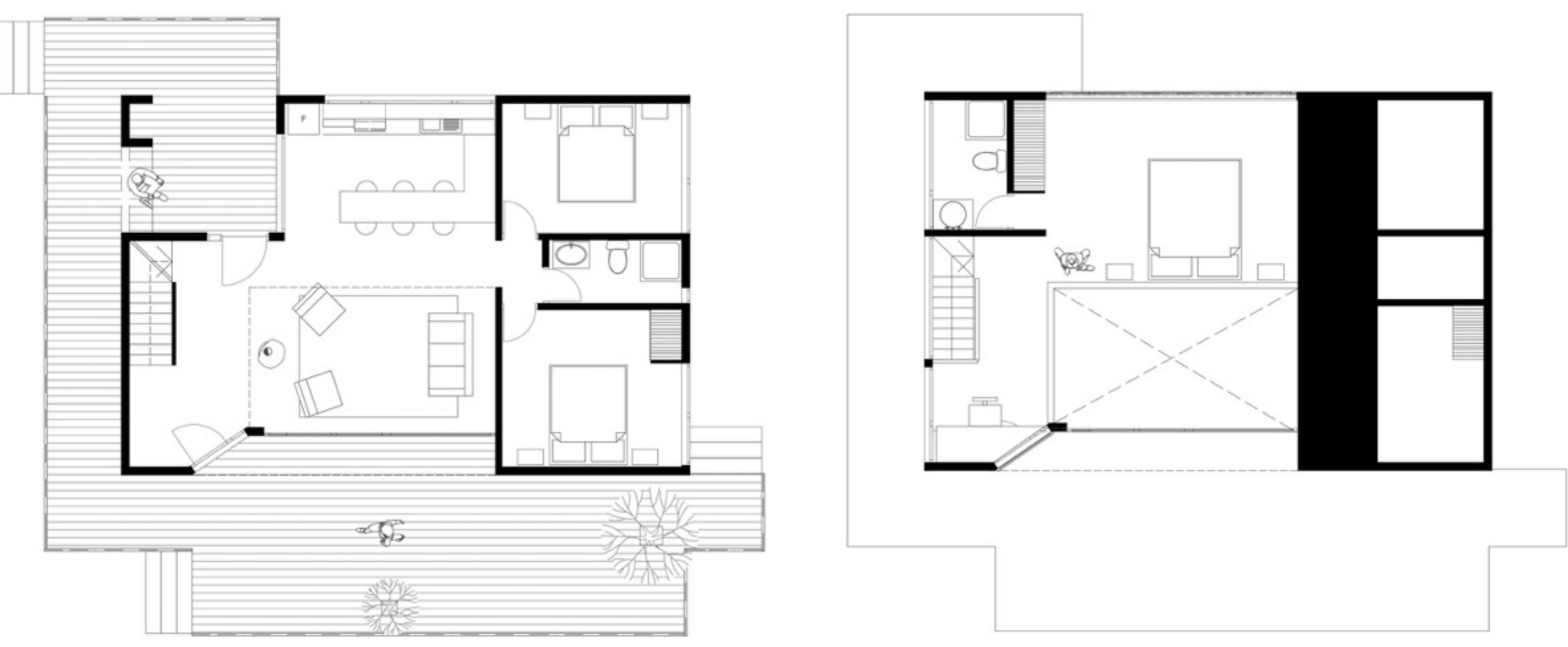

Plantas de distribución arquitectónica. Nivel de acceso (izquierda) y primer nivel (derecha)
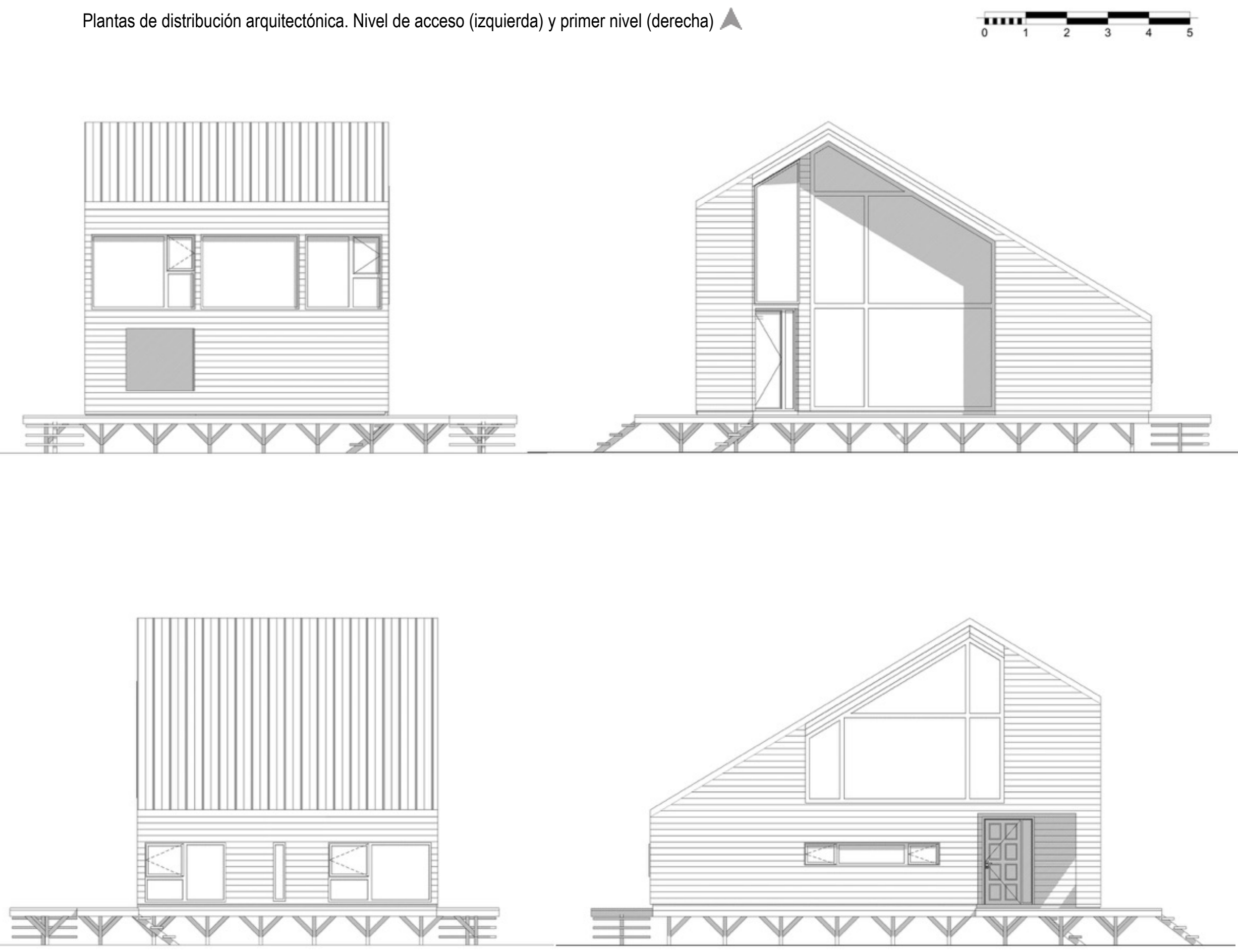

Elevaciones A

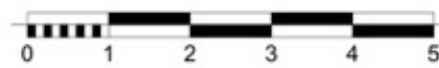



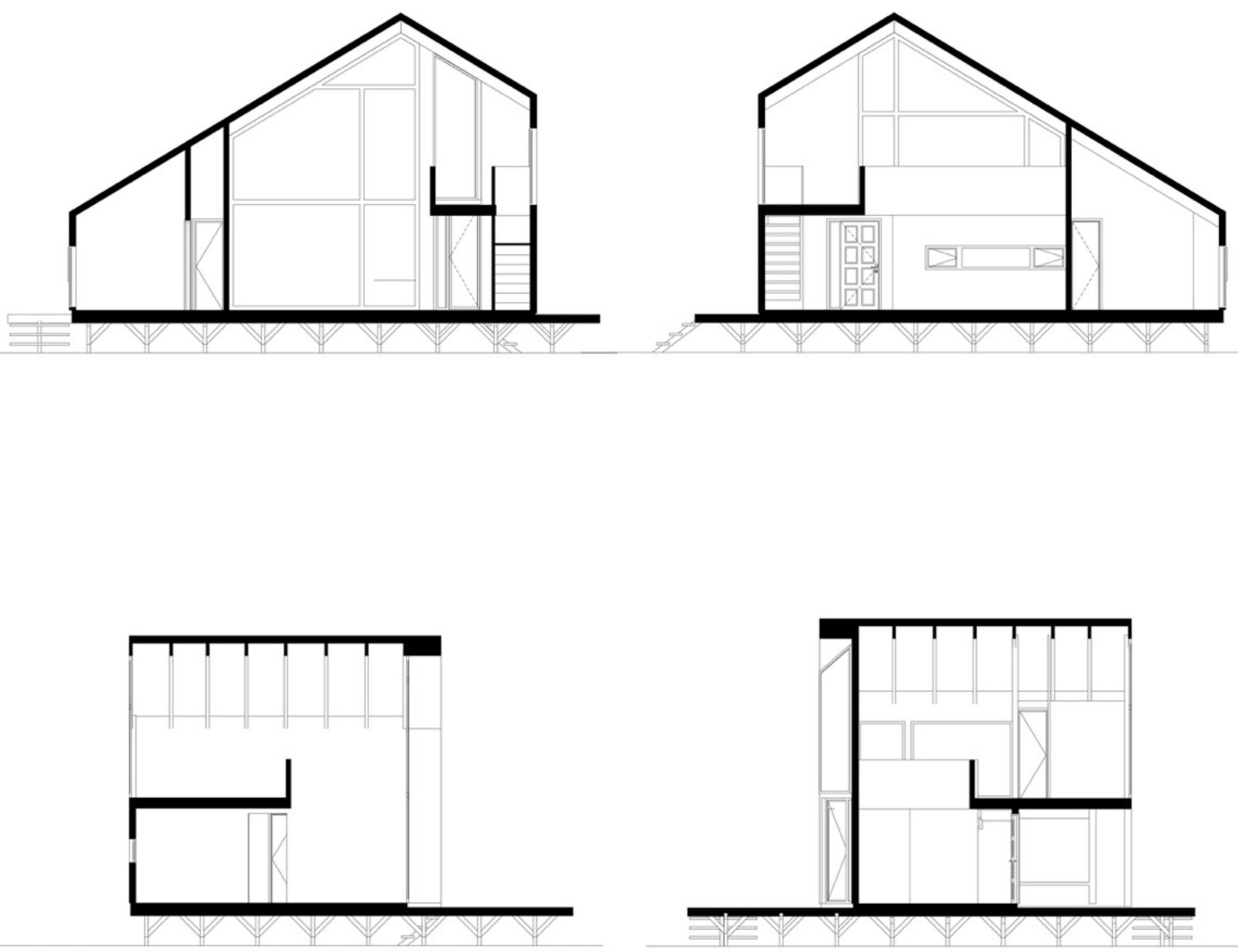

Secciones A

$\mathrm{m}_{0} \boldsymbol{m}_{1}{ }_{2}{ }_{4}$
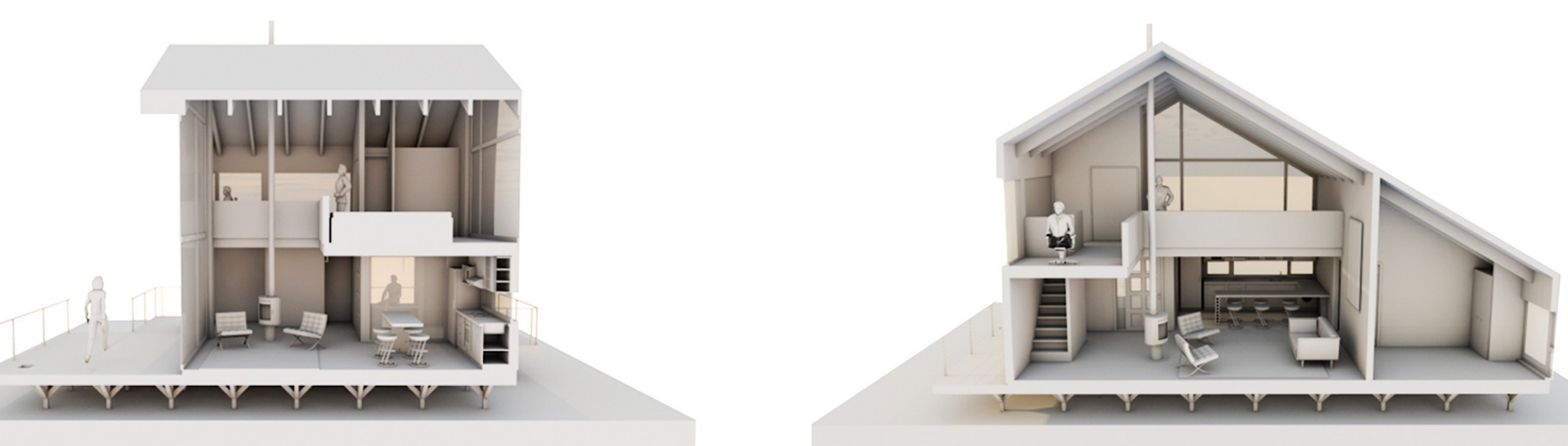

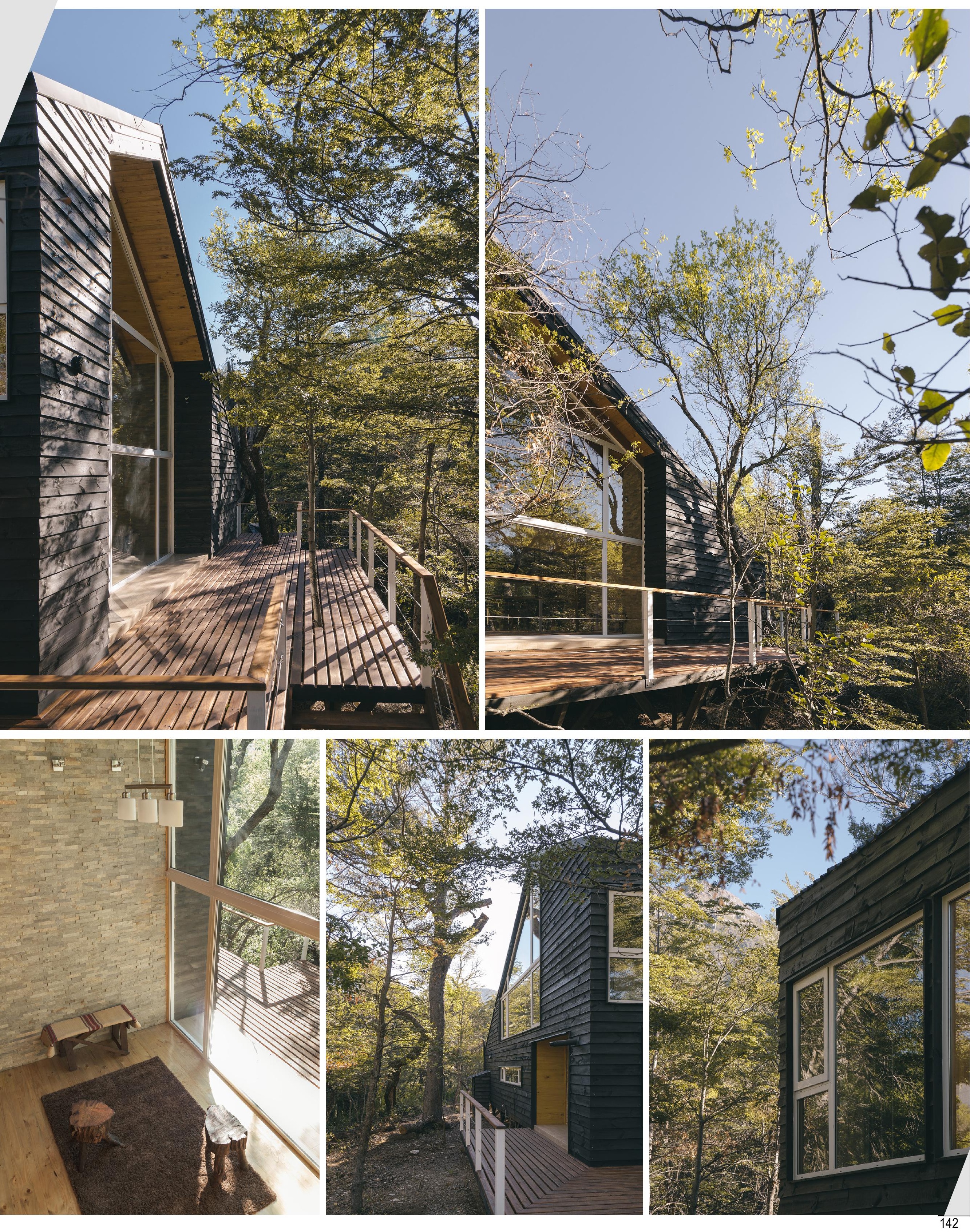

Cabaña ED A 

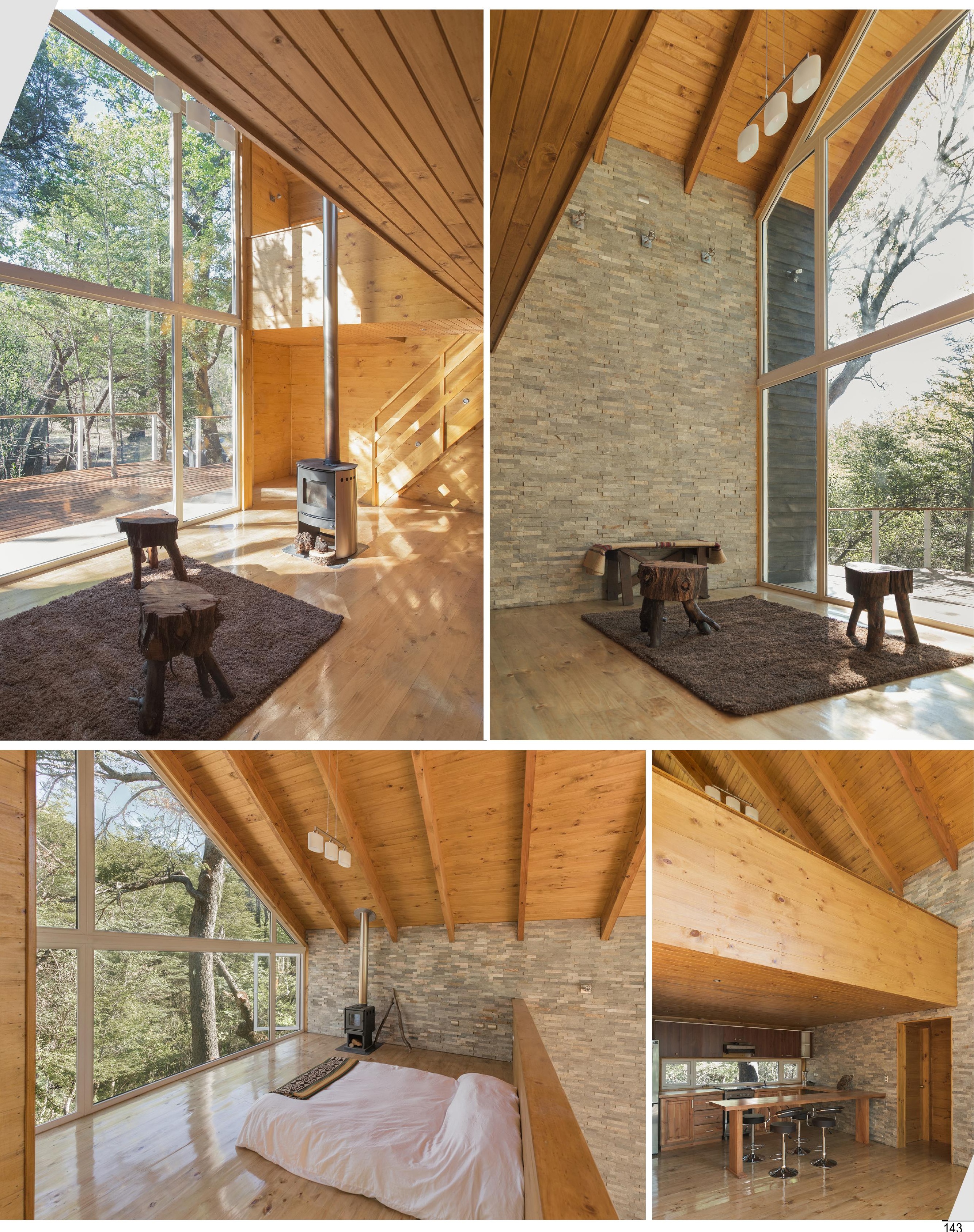

Cabaña ED A 